\title{
sod $A$ and gap Genes as Markers for The Identification of Staphylococcus capitis
}

\author{
Rininta Firdaus ${ }^{1,2 *}$, Hege Hartz Jartun², Miriam Khider ${ }^{2}$ \\ ${ }^{1}$ Faculty of Pharmacy, Universitas Pancasila, Jl. Raya Lenteng Agung No.56-80, Jagakarsa, Jakarta 12640, Indonesia \\ ${ }^{2}$ Department of Clinical and Molecular Medicine, Norwegian University of Science and Technology, Høgskoleringen 1, Trondheim, Norway \\ *Corresponding author. E-mail: rininta.firdaus@gmail.com
}

Received date: Jun 18, 2019; Revised date: Aug 22, 2019; Accepted date: Aug 26, 2019

\section{Abstract}

B ACKGROUND: Rapid and accurate identification of Staphylococcus capitis is required to provide a better prognosis for endocarditis patients and tackle the emergence of multidrug resistant strains of the bacteria in hospitals. The current study was aimed to develop polymerase chain reaction (PCR) assay for specific identification of $S$. capitis using $\operatorname{sodA}$ and gap genes as markers.

METHODS: Five sequences of $\operatorname{sod} A$ and sixteen sequences of gap registered in GeneBank were analysed using bioinformatic tools. PCR primers were designed based on the conserved and specific regions of sodA and gap. Four clinical isolates of S. capitis (named no. 56-59) and six reference strains of coagulase-negative staphylococci (CoNS) species including S. epidermidis ATCC 35984, S. epidermidis 48951I/09, S. lugdunensis 44987/09, S. sciuri 109645I/08, S. warneri 135612/09, S. hominis 114202/08 were used to validate the conventional PCR system.

RESULTS: The current PCR system only amplified the DNA template of $S$. capitis. Current primers specifically targeted $S$. capitis as the agarose images only showed bands from $S$. capitis samples.

CONCLUSION: The sodA and gap genes might serve as effective markers for identification of $S$. capitis using conventional PCR. The PCR assay in the current study was able to identify five clinical isolates of $S$. capitis accurately without mispriming, misamplification and misidentification.

KEYWORDS: Staphylococcus, S. capitis, sodA, gap, PCR

Indones Biomed J. 2019; 11(3): 314-9

\section{Introduction}

Staphylococcus capitis, a coagulase-negative species (CoNS) of staphylococci, has similar morphology to $S$. aureus, but the species lack clumping factors and deoxyribonuclease.(1) Although CoNS are constituents of the normal skin flora of healthy individuals (2), the bacteria have a tendency to colonise and produce biofilm on prosthetic implants such as intravascular lines or cardiac valves (1). The CoNS may be introduced to the medical devices during the device placement, venepuncture, or through breaks in the mucous membrane or skin. CoNS infection mainly leads to prosthetic valve endocarditis, but it possibly causes native valve endocarditis in immunocompromised patients $(<10 \%)$.(3) About $5 \%$ of reported CoNS pathogenic isolates were $S$. capitis. The bacteria has been reported to cause clinical manifestations including endocarditis, pneumonia, urinary tract infection, catheter-related bacteraemia and cellulitis.(4-8)

Recently, S. capitis has emerged to become a worldwide multidrug-resistant clone responsible for nosocomial late-onset sepsis (LOS) in neonatal intensive care units (NICUs).(9) Multiresistant S. capitis LOS cases 
have been reported in several countries including Australia, Belgium, and United Kingdom. A distinguished methicillinresistant $S$. capitis strain named NRCS-A was isolated from several NICUs in France.(10) The strain shows a multidrug resistance profile, including resistance to vancomycin, the first-line antimicrobial agent for LOS. Such a failure to the antibiotic treatment of LOS increase the morbidity of premature neonates in NICUs.

Rapid identification of $S$. capitis in the clinical laboratory is required for differentiation to other staphylococcal and CoNS species, thus specific treatment and initial prevention of dissemination could be performed promptly. Conventional benchtop phenotypic characterisation and biochemical based commercial test kits including fatty acid analysis are commonly used for Staphylococcus species identification. However, the accuracy from these identification techniques may differ to various degrees. PCR assay may provide a better alternative for its higher specificities and sensitivities. The 16S-23S rDNA intergenic space region (11), 16S rRNA (12-14), hsp60 (15-17), sodA (18), tuf (19), rров (20, 21), dnaJ (22), gap (23) were previously used as target genes for identification of Staphylococcus species.

This study was aimed to profile sodA and gap genes as markers for specific differentiation of $S$. capitis from other CoNS species. The sodA and gap genes encode superoxide dismutase A and glyceraldehyde-3-phosphate dehydrogenase, respectively. Both enzymes reduce oxidative stress and maintain the sustenance of the pathogen inside the host. Among Staphylococcus species, the DNA sequence similarities of sodA and gap are $78 \%$ and $60 \%$, respectively.(23) The DNA sequence similarities of $\operatorname{sodA}$ and gap were found to be lower than those of $16 S$ rRNA ( 97\%) (23), tuf (89\%) (19), rроB ( 86\%) (23), hsp60 ( 82\%) (23) and dnaJ (78\%) (22). Here, we developed the PCR methods for these two genes and validated the results with four clinical isolates of $S$. capitis and other six CoNS strains. The developed PCR assay of $\operatorname{sod} A$ and gap in current study may complement other species-level PCR identification of S. capitis and an initial approach for methicillin-resistance typing.

\section{Methods}

\section{Sample}

The DNA sequences of sodA and gap of $S$. capitis were collected from GenBank (Rockville Pike, USA, https:// www.ncbi.nlm.nih.gov/). Five sequences of sodA and 16 sequences of gap were downloaded in FASTA format (txt files) and then further analysed for primer design.

Four isolated clinical strains of $S$. capitis collected from Øya St. Olavs Hospital (Trondheim, Norway) named no. 56, 57, 58, and 59 were used to validate the PCR assay. The isolates were collected retrospectively from NICU infants in 2008 regardless of their methicillin resistance in the microbiological records. Identification of bacterial isolates was initially performed by Gram staining, catalase and benzidine tests, and the determination of anaerobic acid production from glucose. In addition, a simple scheme was performed according to previous reference method. $(24,25)$ S. capitis was characterized as Gram positive, coagulase negative, urease positive, pyrrolidonyl aminopeptidase (PYR) positive, trehalose negative, mannitol positive, and susceptible to novobiocin. The bacterial isolates were also identified as $S$. capitis by amplification of $t u f$ gene as previously described.(19)

Six strains from other CoNS species were also used in this study, including S. epidermidis ATCC 35984, S. epidermidis 489511/09, S. lugdunensis 44987/09, S. sciuri $109645 \mathrm{I} / 08$, S. warneri $135612 / 09$ and S. hominis $114202 / 08$. All strains were cultured in trypticase soy agar and incubated $37^{\circ} \mathrm{C}$ for 24 hours. Bacterial cells were harvested in sterile saline for DNA extraction.

\section{DNA Sequence Analysis}

Multiple alignments by Clustal Omega (European Bioinformatics Institute, Hinxton, UK, https://www.ebi. ac.uk/Tools/msa/clustalo/) were each performed for $S$. capitis sodA and gap gene sequences to look for the highest similarity area and avoid single nucleotide polymorphisms (SNPs). The particular area were aligned to sequences from other Staphylococcus species. Specific regions of S. capitis in sodA and gap sequences were analysed for PCR primer design. Alignments were performed using basic local alignment sequence type (BLAST) online (https://blast. ncbi.nlm.nih.gov/Blast.cgi).

\section{PCR Primer Design}

PCR primers were design based on the specific area analysed from the multiple alignments. Primers were generated by OLIGO Primer Analysis Software (Molecular Biology Insights Inc., Colorado, USA) with preferred values (length 18-22 nucelotides, GC content: 40-60\%, melting temperature $\left(\mathrm{T}_{\mathrm{m}}\right) 50-60^{\circ} \mathrm{C}, \mathrm{T}_{\mathrm{m}}$ difference between primers $<5^{\circ} \mathrm{C}, \mathrm{T}_{\mathrm{m}}$ difference between primers and PCR products $<22^{\circ} \mathrm{C}$ ). Primer candidates were tested by BLAST to determine sensitivity and specificity. The 
selected primers were produced by Oligo Sigma (Oslo, Norway).

\section{PCR Assay}

The number of bacteria $\left(2 \times 10^{9}\right.$ cells $)$ was determined by measuring the optical density $\left(\mathrm{OD}_{600 \mathrm{~nm}}\right)$. DNeasy ${ }^{\circledR}$ Blood and Tissue Kit (Qiagen, Oslo, Norway) was utilised to extract the total DNA. The quality of DNA samples was verified by measuring the absorption ratio using a Nanodrop ND-1000 spectrophotometer at 260/280 $\mathrm{nm}$ wavelength (NanoDrop Technologies, Oslo, Norway).

The concentration of DNA template was 1:10 dilution. The PCR reaction includes $5 \mu \mathrm{L}$ of $10 \times$ PCR buffer with $\mathrm{MgCl}_{2}$ (Thermo Fisher Scientific, Oslo, Norway), $2.5 \mu \mathrm{L}$ of dNTP $(1 \mathrm{mM}), 0.2 \mu \mathrm{L}$ of AmpliTaqGold (Thermo Fisher Scientific, Oslo, Norway), $2 \mu \mathrm{L}$ of each PCR primer (each $\left.100 \mathrm{ng} \mathrm{L}^{-1}\right), 36.3 \mu \mathrm{L}$ of $\mathrm{ddH}_{2} \mathrm{O}$, and $2 \mu \mathrm{L}$ of DNA template. PCR was performed using GeneAmp PCR System 9700 (Applied Biosystem, Oslo, Norway). The optimised PCR condition used in current study were initial denaturation $95^{\circ} \mathrm{C}$ for 10 minutes followed by 35 cycles denaturation $94^{\circ} \mathrm{C}$ for 60 seconds, annealing $58^{\circ} \mathrm{C}$ for 60 seconds, and extension $72^{\circ} \mathrm{C}$ for 30 seconds. Extra elongation step were also used at $72^{\circ} \mathrm{C}$ for 7 minutes and $10^{\circ} \mathrm{C}$ for an indefinite time.

PCR product was separated by gel electrophoresis in 2\% agarose gel using SYBR Safe (Thermo Fisher Scientific, Oslo, Norway) as gel stain. After immersing the gel with $1 \%$ Tris-acetate-EDTA (TAE) buffer; samples containing $1 \times$ DNA loading dye were loaded alongside $1 \mathrm{~kb}$ Plus DNA Ladder (Invitrogen, Oslo, Norway). The gel was run at $80 \mathrm{~V}$ for 45 minutes and visualized using Gel Doc XR plus (Biorad, Watford, UK). The quantification of visualised PCR products was adopted from previous study.(26) Band intensities were quantified using Image J software (National Institutes of Health, Madison, USA). Each band density was compared to the ladder density (relative density).

\section{Results}

\section{DNA Sequence Analysis}

Specificity of a gene is determined by DNA sequence similarities of targeted and non-targeted genes. The sequence similarities between five sequences of $\operatorname{sod} A$ genes were $99-100 \%$ (Supplement 1), while the sequence similarities between sixteen sequences of gap genes were 97-100\% (Supplement 2). The SNP areas were avoided for the primer design. The highly conserved area were then aligned to other Staphylococcus species using BLAST. The specific area for sodA and gap are presented in Supplement 3 and Supplement 4, respectively.

\section{Primer Design}

The PCR primers targeted for specific regions of $\operatorname{sodA}$ and gap were designed semi-automatic (manually) using OLIGO software (Table 1). All primers were consist of 20 nucleotides. The GC content and $\mathrm{T}_{\mathrm{m}}$ of the primers were on the range of $45-56 \%$ and $49.7-59.4^{\circ} \mathrm{C}$, respectively. The $\mathrm{Tm}$ difference among primers of each gene were less than $5^{\circ} \mathrm{C}$. Hairpins, mispriming, and self-dimerization were not detected.

\section{PCR Assay}

The primer application in PCR assay of sodA and gap for the identification of $S$. capitis was performed with conventional GeneAmp PCR System 9700 (Applied Biosystem, USA). The primers were validated using several isolates of $S$. capitis (named no. 56-59), and referral strains from other Staphylococcus species (S. epidermidis, S. lugdunensis, S. sciuri, S. warneri and $S$. hominis). Figure 1 and Figure 2 show the agarose images from PCR assays of $\operatorname{sod} A$ and gap, respectively. Bands appeared only from S. capitis isolates. Primers were specific to strains of $S$. capitis and these primers did not generate any products from other Staphylococcus strains used in current study. Still, more

Table 1. PCR primers sequences targeted sodA and gap gene for $\boldsymbol{S}$. capitis identification. The primers were generated by OLIGO software (Molecular Biology Insights, Colorado, USA).

\begin{tabular}{llccccc}
\hline \multicolumn{2}{c}{ Gene } & Primer Sequence & Length & $\mathbf{T}_{\mathbf{m}}$ & GC-content & PCR Product \\
\hline \multirow{2}{*}{ sodA } & Forward & CTCAGCAGTTGAAGGAACAG & 20 & $57.8^{\circ} \mathrm{C}$ & $56 \%$ & \multirow{2}{*}{$275 \mathrm{bp}$} \\
\cline { 3 - 7 } & Reverse & CTAACCATGCCCAACCAGAT & 20 & $59.4^{\circ} \mathrm{C}$ & $50 \%$ & \\
\hline \multirow{2}{*}{ gap } & Forward & ATCGATGGTGGATTCCGTGT & 20 & $51.8^{\circ} \mathrm{C}$ & $50 \%$ & \multirow{2}{*}{$270 \mathrm{bp}$} \\
\cline { 3 - 6 } & Reverse & AGAAGCACCTGATACAACTG & 20 & $49.7^{\circ} \mathrm{C}$ & $45 \%$ & \\
\hline
\end{tabular}




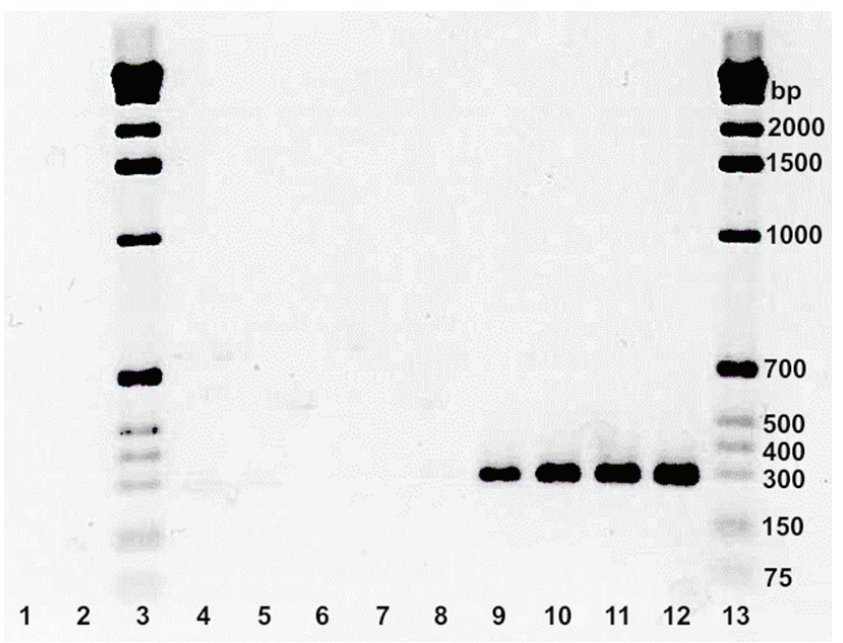

Figure 1. Agarose gel image of PCR product from identification assay of sodA gene. Lane 1: negative control $\left(\mathrm{ddH}_{2} \mathrm{O}\right)$; Lane 2: $\mathrm{S}$. Epidermidis ATCC 35984; Lane 3: 1 kb Plus DNA Ladder; Lane 4: S. epidermidis 48951I/09; Lane 5: S. lugdunensis 44987/09; Lane 6: S. sciuri 109645I/08; Lane 7: S. warneri 135612/09; Lane 8: $S$. hominis 114202/08; Lane 9: S. capitis isolate no. 56; Lane 10: $S$. capitis isolate no. 57; Lane 11: S. capitis isolate no. 58; Lane 12: S. capitis isolate no. 59; Lane 13: $1 \mathrm{~kb}$ Plus DNA Ladder.

samples from other Staphylococcus strains are needed to validate the specificity of current primers.

The band densities are presented in Table 2. Area densities lower than 500 were considered as background. In general, the area densities of visualised bands in all gels were between 9702 and 15861. S. capitis isolate no. 56 had the lowest area of sodA and the highest area of gap. In contrast, $S$. capitis isolate no. 59 had the highest area of sodA and the lowest area of gap. S. capitis isolate no. 57 and 58 had relative similar area densities in both sodA and gap gels.

\section{Discussion}

In current study, the sodA and gap genes were used as markers for identification of $S$. capitis because the genes' sequences are well-conserved within the species, yet contain variable domains to discriminate between close-related species. The other gene, $t u f$, has been used as a marker for a regular identification of $S$. capitis in the hospital laboratory in regards to the previous published methods. $(10,19,23)$ However, the amplification of $t u f$ was unable to discriminate S. epidermidis strains entirely probably due to the close relationship between $S$. capitis and S. epidermidis as shown in tuf-based phylogenetic tree (bootstrap values of 64\%) generated in previous study.(23) Thus, development of PCR system using sodA and gap as markers would complement the established tuf-based assay.

The sodA and gap had been used as markers for identification of Staphylococcus species. A pair of general primers had been proposed to detect the internal fragment of sodA which represents approximately $83 \%$ of all sequence variants of $\operatorname{sodA}$.(18) Partial gene sequencing of gap have been developed in previous study as a molecular tool for taxonomical analysis of Staphylococcus species.(23) While previous studies were aimed to detect Staphylococcus species and CoNS strains (23), the PCR system in current study was designed to specifically identify $S$. capitis.

Phylogenetic trees of Staphylococcus species had been generated in previous study based on $\operatorname{sod} A$ and gap genes. (23) The phylogenetic tree of sodA showed that $S$. capitis was in the same cluster with $S$. caprae, $S$. warneri and $S$. epidermidis, while the phylogenetic tree of gap showed a close relationship between $S$. capitis, S. warneri, $S$. epidermidis and S. aureus. Current PCR system have been validated using isolate strains of $S$. capitis, and reference strains of other Staphylococcus species including S. warneri, S. epidermidis, S. lugdunensis, S. sciuri and S. hominis. The system so far have been able to distinguish $S$. capitis from close related species $S$. warneri and S. epidermidis, also from distant Staphylococcus species S. lugdunensis, S. sciuri and S. hominis . Future study validating the PCR

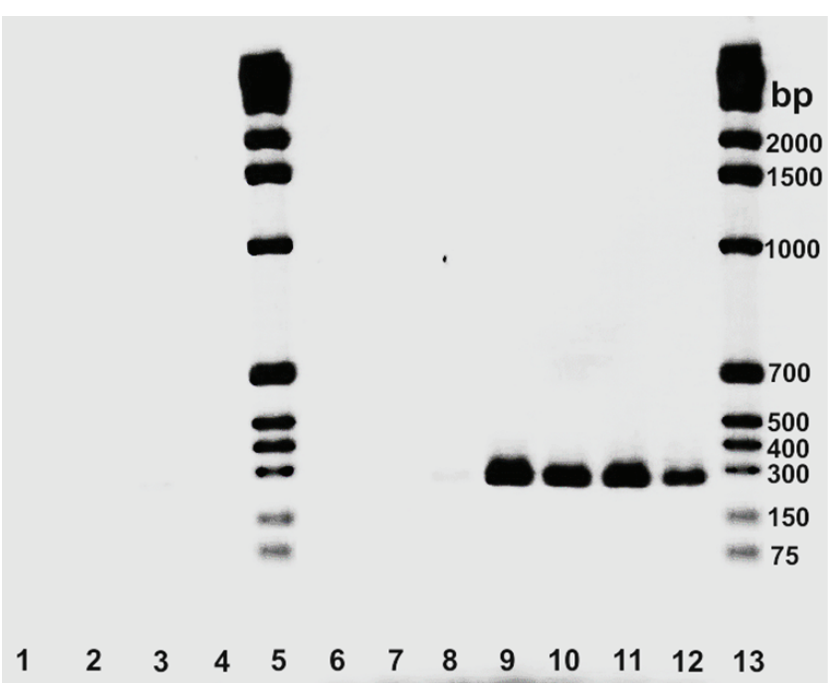

Figure 2. Agarose gel image of PCR product from identification assay of gap gene. Lane 1: negative control $\left(\mathrm{ddH}_{2} \mathrm{O}\right)$; Lane 2 : $\mathrm{S}$. Epidermidis ATCC 35984; Lane 3: 1 kb Plus DNA Ladder; Lane 4: S. epidermidis 48951I/09; Lane 5: S. lugdunensis 44987/09; Lane 6: S. sciuri 109645I/08; Lane 7: S. warneri 135612/09; Lane 8: S. hominis 114202/08; Lane 9: S. capitis isolate no. 56; Lane 10: $S$. capitis isolate no. 57; Lane 11: S. capitis isolate no. 58; Lane 12: S. capitis isolate no. 59; Lane 13: $1 \mathrm{~kb}$ Plus DNA Ladder. 
Table 2. The band densities of sodA and gap genes. Band densities of sodA (Figure 1) and gap (Figure 2) were analysed and quantified using Image $\mathbf{J}$ software (National Institutes of Health, Madison, USA).

\begin{tabular}{lccccc}
\hline \multirow{2}{*}{ Sample } & \multicolumn{2}{c}{ sodA } & \multicolumn{2}{c}{ gap } \\
\cline { 2 - 3 } \cline { 5 - 6 } & Area Density & $\begin{array}{c}\text { Relative Density } \\
\text { to Marker }\end{array}$ & & Area Density & $\begin{array}{c}\text { Relative Density } \\
\text { to Marker }\end{array}$ \\
\hline $\mathrm{ddH}_{2} \mathrm{O}$ & 236.849 & 0.184 & & 120.950 & 0.032 \\
S. epidermidis ATCC 35984 & 29.536 & 0.023 & & 267.607 & 0.071 \\
S. epidermidis 48951I/09 & 336.506 & 0.262 & & 174.950 & 0.047 \\
S. lugdunensis 44987/09 & 56.950 & 0.044 & & 145.536 & 0.039 \\
S. sciuri 109645I/08 & 65.778 & 0.051 & & 228.607 & 0.061 \\
S. warneri 135612/09 & 101.950 & 0.079 & & 466.577 & 0.124 \\
S. hominis 114202/08 & 409.335 & 0.319 & & 35.950 & 0.010 \\
S. capitis isolate no. 56 & 9790.418 & 7.624 & & 11686.520 & 3.105 \\
S. capitis isolate no. 57 & 13288.370 & 10.348 & & 13233.290 & 3.516 \\
S. capitis isolate no. 58 & 14011.850 & 10.911 & & 13389.890 & 3.557 \\
S. capitis isolate no. 59 & 15859.083 & 12.349 & 9702.338 & 2.578 \\
\hline
\end{tabular}

system with strains of S. caprae and S. auerus would fill the gaps of current findings. Validation of the primers in realtime PCR would also needed for further study.

The sodA and gap genes from S. capitis have sequence similarities less than $90 \%$ to $S$. warneri and S. epidermidis. Mispriming may easily occur if the PCR primers are not specific. To ensure the sensitivity of the PCR system, the primers should target the conserved regions of the gene and avoid SNPs area. However, the primers should also target the unique area specific to $S$. capitis to differentiate it to other Staphylococcus species. Thus, the particular area match to these two criteria were carefully analysed and further processed by the OLIGO software with specific preferences. The analysis using OLIGO did not reveal any 'run' and 'repeat' with $\mathrm{T}_{\mathrm{m}}$ difference not more than $3^{\circ} \mathrm{C}$. The primer-dimer bonds were not detected in the designed primers. The analysis using BLAST again showed that the primers were specific, and no mismatch was detected with the non-targeted DNA.

The PCR condition had been optimised to choose the effective concentration of template DNA (Supplement 5 ). The undiluted concentration caused tailing on the gel, therefore 10 -fold dilution was considered as the optimum concentration. The annealing temperature also had been optimised from $50-62^{\circ} \mathrm{C}$ (Supplement 6). The optimum temperature was achieved at $58^{\circ} \mathrm{C}$ to avoid artefacts.

The visualised agarose gels showed bands only from $S$. capitis samples (isolate no. 56-59). A single band of $\sim 300$ bp appeared from each $S$. capitis isolate. The variation of band densities was occurred from PCR products of isolates no. 56 and 59, as the two isolates showed the lowest and highest area densities for sodA and gap. It would be tempted to state that strong expression in $\operatorname{sodA}$ might contribute to the thin band appearance on gap. However, such variation might happen due to different loading conditions of the sample. Still, the primers of the assays was specifically amplify the targeted gene sequence. Future study on defining the sequence of each band was needed to fully answer the diverse densities.

The dnaJ and hsp60 are other potential markers for identification of $S$. capitis. $(22,23)$ The dnaJ has mean similarity $77.6 \%$ among Staphylococcus species and had been reported showing remarkable discrimination except for the most similar pairs such as $S$. condimenti and $S$. carnosus (90.9\%), S. intermedius and S. delphini (92.3\%), and S. pulvereri and S. vitulinus (99.3\%).(22) The hsp60 has mean similarity $82 \%$ among Staphylococcus species. (23) Although the mean similarity is higher than dnaJ, sodA and gap, the hsp60 had been reported as an effective marker to identify specifically $S$. capitis subsp. ureolyticus as well as $S$. sciuri, S. caseolyticus, S. hominis, S. warneri, S. hyicus and $S$. haemolyticus (17).

The developed PCR assay in current study provides higher specificities and sensitivities than conventional benchtop phenotypic characterisation and biochemical tests for species-level identification of $S$. capitis. The 
amplification of sodA and gap may complement the tufbased PCR assay. The PCR identification would become an initial step for methicillin-resistance typing of clinical isolates of $S$. capitis.

\section{Conclusion}

The sodA and gap genes might serve as effective markers for identification of $S$. capitis using conventional PCR. The PCR assay in the current study was able to identify five clinical isolates of $S$. capitis accurately without mispriming, misamplification and mis-identification.

\section{References}

1. Humphreys H. Staphylococcus. In: Greenwood D, Slack R, Barer M, Irving W, editors. Medical Microbiology. London: Churchill Livingstone; 2012. p. 176-82.

2. Maggs AF, Pennington TH. Temporal study of staphylococcal species on the skin of human subjects in isolation and clonal analysis of Staphylococcus capitis by sodium dodecyl sulfate-polyacrylamide gel electrophoresis. J Clin Microbiol. 1989; 27: 2627-32.

3. Al Hennawi HET, Mahdi EM, Memish ZA. Native valve Staphylococcus capitis infective endocarditis: a mini review. Infection. 2019; [nv]: 1-3. doi: 10.1007/s15010-019-01311-8.

4. Caputo GM, Archer GL, Calderwood SB, DiNubile MJ, Karchmer AW. Native valve endocarditis due to coagulase-negative staphylococci. Clinical and microbiologic features. Am J Med. 1987; 83: 619-25.

5. Etienne J, Eykyn SJ. Increase in native valve endocarditis caused by coagulase negative staphylococci: an Anglo-French clinical and microbiological study. Br Heart J. 1990; 64: 381-4.

6. Mainardi JL, Lortholary O, Buu-Hoi A, Desplaces N, Goldstein F, Gutmann L, et al. Native valve endocarditis caused by Staphylococcus capitis. Eur J Clin Microbiol Infect Dis. 1993; 12: 789-91.

7. Chu VH, Cabell CH, Abrutyn E, Corey GR, Hoen B, Miro JM, et al. Native valve endocarditis due to coagulase-negative staphylococci: report of 99 episodes from the International Collaboration on Endocarditis Merged Database. Clin Infect Dis. 2004; 39: 1527-30.

8. Chu VH, Woods CW, Miro JM, Hoen B, Cabell CH, Pappas PA, et al. Emergence of coagulase-negative staphylococci as a cause of native valve endocarditis. Clin Infect Dis. 2008; 46: 232-42.

9. Butin M, Rasigade JP, Martins-Simoes P, Meugnier H, Lemriss $\mathrm{H}$, Goering RV, et al. Wide geographical dissemination of the multiresistant Staphylococcus capitis NRCS-A clone in neonatal intensive-care units. Clin Microbiol Infect. 2016; 22: 46-52.

10. Rasigade JP, Raulin O, Picaud JC, Tellini C, Bes M, Grando J, et al. Methicillin-resistant Staphylococcus capitis with reduced vancomycin susceptibility causes late-onset sepsis in intensive care neonates. PLoS One. 2012; 7: e31548. doi: 10.1371/journal. pone. 0031548 .

11. Mendoza M, Meugnier H, Bes M, Etienne J, Freney J. Identification of Staphylococcus species by 16S-23S rDNA intergenic spacer PCR analysis. Int J Syst Bacteriol. 1998; 48: 1049-55.

12. Becker K, Harmsen D, Mellmann A, Meier C, Schumann P, Peters G, et al. Development and evaluation of a quality-controlled ribosomal sequence database for $16 \mathrm{~S}$ ribosomal DNA-based identification of Staphylococcus species. J Clin Microbiol. 2004; 42: 4988-95.

13. Gribaldo S, Cookson B, Saunders N, Marples R, Stanley J. Rapid identification by specific PCR of coagulase-negative staphylococcal species important in hospital infection. J Med Microbiol. 1997; 46 : 45-53.

14. Skow A, Mangold KA, Tajuddin M, Huntington A, Fritz B, Thomson RB Jr., et al. Species-level identification of staphylococcal isolates by real-time PCR and melt curve analysis. J Clin Microbiol. 2005; 43: $2876-80$.

15. Kwok AY, Chow AW. Phylogenetic study of Staphylococcus and Macrococcus species based on partial hsp60 gene sequences. Int J Syst Evol Microbiol. 2003; 53: 87-92.

16. Kwok AY, Su SC, Reynolds RP, Bay SJ, Av-Gay Y, Dovichi NJ, et al. Species identification and phylogenetic relationships based on partial HSP60 gene sequences within the genus Staphylococcus. Int J Syst Bacteriol. 1999; 49: 1181-92.

17. Goh SH, Santucci Z, Kloos WE, Faltyn M, George CG, Driedger D, et al. Identification of Staphylococcus species and subspecies by the chaperonin 60 gene identification method and reverse checkerboard hybridization. J Clin Microbiol. 1997; 35: 3116-21.

18. Poyart C, Quesne G, Boumaila C, Trieu-Cuot P. Rapid and accurate species-level identification of coagulase-negative staphylococci by using the sodA gene as a target. J Clin Microbiol. 2001; 39: 4296301.

19. Martineau F, Picard FJ, Ke D, Paradis S, Roy PH, Ouellette M, et al. Development of a PCR assay for identification of staphylococci at genus and species levels. J Clin Microbiol. 2001; 39: 2541-7.

20. Drancourt M, Raoult D. rpoB gene sequence-based identification of Staphylococcus species. J Clin Microbiol. 2002; 40: 1333-8.

21. Mellmann A, Becker K, von Eiff C, Keckevoet U, Schumann P, Harmsen D. Sequencing and staphylococci identification. Emerg Infect Dis. 2006; 12: 333-6.

22. Shah MM, lihara $\mathrm{H}$, Noda $\mathrm{M}$, Song SX, Nhung PH, Ohkusu K, et al. dnaJ gene sequence-based assay for species identification and phylogenetic grouping in the genus Staphylococcus. Int J Syst Evol Microbiol. 2007; 57: 25-30.

23. Ghebremedhin B, Layer F, Konig W, Konig B. Genetic classification and distinguishing of Staphylococcus species based on different partial gap, 16S rRNA, hsp60, rpoB, sodA, and tuf gene sequences. J Clin Microbiol. 2008; 46: 1019-25.

24. De Paulis AN, Predari SC, Chazarreta CD, Santoianni JE. Fivetest simple scheme for species-level identification of clinically significant coagulase-negative staphylococci. J Clin Microbiol. 2003; 41: 1219-24.

25. Kloos WE, Bannerman TL. Staphylococcus and micrococcus In: Murray PR, Barron EJ, Pfaller MA, Tenover FC, Yolken RH, editors. Manual of Clinical Microbiology. 6th ed. Washington, D.C.: ASM Press; 1995. p.264-82.

26. Antiabong JF, Ngoepe MG, Abechi AS. Semi-quantitative digital analysis of polymerase chain reaction-electrophoresis gel: Potential applications in low-income veterinary laboratories. Vet World. 2016; 9: 935-9.

27. Lingappa JR, Al-Rabeah AM, Hajjeh R, Mustafa T, Fatani A, AlBassam T, et al. Serogroup W-135 meningococcal disease during the Hajj, 2000. Emerging Infectious Diseases. 2003; 9: 665-71. 